\title{
Oral administration of starting materials for in vivo synthesis of antibacterial gold nanoparticles for curing remote infections
}

Le Wang ${ }^{1,2}$, Junchuan Yang ${ }^{3}$, Sixiang $\mathrm{Li}^{2}$, Qizhen $\mathrm{Li}^{2}$, Shaoqin Liu ${ }^{1, *}$, Wenfu Zheng ${ }^{3, *}$, Xingyu Jiang ${ }^{1,2, *}$

${ }^{1}$ School of Life Science and Technology, Harbin Institute of Technology, 2 Yikuang Road, Nangang District, Harbin, 150001, P. R. China

2 Department of Biomedical Engineering, Southern University of Science and Technology, No. 1088 Xueyuan Rd, Nanshan District, Shenzhen, Guangdong 518055, P. R. China

${ }^{3}$ The GBA National Institute for Nanotechnology Innovation, CAS Key Lab for Biological Effects of Nanomaterials and Nanosafety, National Center for NanoScience and Technology, Beijing, 100190, P. R. China

\section{Experimental Section}

Materials

Aminophenylboronic acid (ABA, ortho-position (2ABA), meta-position (3ABA), para-position (4ABA), hydrochloride, $\mathrm{Mw}=173.41)$, tetrachloroauric acid $\left(\mathrm{HAuCl}_{4} \cdot 3 \mathrm{H}_{2} \mathrm{O}\right)$, hydrochloric acid $(\mathrm{HCl})$, sodium hydroxide $(\mathrm{NaOH})$ and Tween 80 were from Sigma (USA). Phenylboronic acid (PBA, Mw = 121.93) and aniline (Mw = 93.14) were from Alfa Aesar (USA). All other chemicals and solvents were reagent grade.

\section{Preparation and Characterization of IA-GNPs}

We used ABA to reduce $\mathrm{HAuCl}_{4} \cdot 3 \mathrm{H}_{2} \mathrm{O}$ by the one-pot synthesis method in double-distilled water. We mixed the $\mathrm{HAuCl}_{4} \cdot 3 \mathrm{H}_{2} \mathrm{O}(0.05 \mathrm{mmol})$ and Tween 80 (30 $\mathrm{mg})$ in $10 \mathrm{~mL}$ water for $10 \mathrm{~min}$ in an ice-water bath or at room temperature. We added ABA $(0.05 \mathrm{mmol})$ in the mixture dropwise with different stirring $(100,500$, or 1000 rpm) speeds. The color of the solution turned brown immediately. We utilized $\mathrm{HCl}$ to adjust the pondus hydrogenii $(\mathrm{pH})$ of the solution in the acidic range, and $\mathrm{NaOH}$ to adjust the alkaline range. To explore the role of the two functional groups (boronic acid group, amine group) in ABA in the synthesis progress, we used the above synthetic method to prepare the PBA or aniline-capped GNPs using $\mathrm{NaBH}_{4}$ as reducing agent. We further explored the effect of acidic condition on the activity of amino groups on ABA. We prepared 4ABA and $\mathrm{HAuCl}_{4}$ solutions with $\mathrm{H}_{2} \mathrm{O}$ or $\mathrm{HCl}$ $\left(\mathrm{pH}=2\right.$ ) and added the 4ABA (dissolved in $\mathrm{H}_{2} \mathrm{O}$ or in $\mathrm{HCl}$ ) in $\mathrm{HAuCl}_{4}$ (dissolved in $\mathrm{H}_{2} \mathrm{O}$ or in $\mathrm{HCl}$ ) to observe the color change of the solutions at different time points. We dialyzed the nanoparticles with a dialysis bag (14 kDa Mw cut-off, Solarbio) to remove the unreacted chemicals for $24 \mathrm{~h}$. We sterilized the nanoparticles by filtering 
the solution through a $0.22-\mu \mathrm{m}$ filter (Millipore) and stored them at $4{ }^{\circ} \mathrm{C}$ until use.

We explored the particle size and Zeta potential of the nanoparticles synthesized under different conditions by transmission electron microscopy (TEM, Tecnai G2 20 S-TWIN, FEI company, USA) and dynamic light scattering (DLS, Malvern Company, England). We employed X-ray photoelectron spectroscopy (XPS ESCALAB 250Xi, Thermo Fisher Scientific, USA) to characterize the chemical element of GNPs. We determined concentrations of all types of GNPs by testing elemental gold with inductively coupled plasma analyses (ICP, iCAP 6300, Thermo Scientific, USA). We used UV-vis spectrophotometer (Shimadzu UV2450, Japan) to determine the UV-vis absorption of the nanoparticle solution.

\section{Antibacterial Activity and Mechanisms of IA-GNPs}

We cultured the bacteria in the Luria-Bertani (LB) medium (10g/L casein tryptone, 5 $\mathrm{g} / \mathrm{L}$ yeast extract, and $10 \mathrm{~g} / \mathrm{L} \mathrm{NaCl}, \mathrm{pH}=7$ ) at $37^{\circ} \mathrm{C}$ with the original bacterial concentration of $1 \times 10^{4}$ colony-forming units $(\mathrm{CFU} / \mathrm{mL})$. We diluted the solution of lA-GNPs 2-128 times with nutrient broth inoculated with the Gram-negative bacteria which reached a final volume of $100 \mu \mathrm{L}$. We observed the minimum inhibitory concentration (MIC) of the microbe after $24 \mathrm{~h}$, setting the control group with levofloxacin (a common oral antibiotic, $\mathrm{Mw}=397.83$, Solarbio). To test the antibiotic effects of the nanoparticles directly, we selected Gram-negative bacteria (Escherichia coli, E. coli, ATCC 11775; Klebsiella Pneumonia, K. p, ATCC 13883; and Pseudomonas aeruginosa, P. a, ATCC 27853) and MDR clinical isolates (MDR E. coli, MDR K. p, and MDR P. a) which were isolated from patient's urine or saliva (Beijing You'an Hospital) with patient's consent as microbial models. We used lA-GNPs $(20 \mu \mathrm{g} / \mathrm{mL})$ to incubate with bacteria at $37^{\circ} \mathrm{C}$ for $24 \mathrm{~h}$ or $48 \mathrm{~h}$ on a shaking bed at $260 \mathrm{rpm}$. We analyzed the antibacterial activities of lA-GNPs by determining the optical density at $600 \mathrm{~nm}(\mathrm{OD} 600 \mathrm{~nm})$ based on the turbidity of the bacterial suspension. We fixed lA-GNPs-treated bacterial samples with $2.5 \%$ glutaraldehyde and ethanol dehydration (30\%, 50\%, 70\%, 80\%, 90\%, 95\%, and 100\% (v/v, in water) in sequence for scanning electron microscopy (SEM, S8220, Japan) characterization. For TEM imaging, the samples were fixed by $2.5 \%$ glutaraldehyde and $0.1 \%$ osmic acid, dehydrated with ethanol (30\%, 50\%, 70\%, 80\%, 90\%, 95\%, and $100 \%$, v/v, in water) in sequence, and further cut into ultrathin slices and stained with $2 \%$ uranyl acetate and $0.2 \%$ lead citrate.

To further explore the antibiotic mechanisms of lA-GNPs, we evaluated the permeability of cell membranes in the presence of lA-GNPs. We treated E. coli or MDR E. coli with lA-GNPs $(6 \mu \mathrm{g} / \mathrm{mL}$ and $12 \mu \mathrm{g} / \mathrm{mL})$ at $37{ }^{\circ} \mathrm{C}$ for $4 \mathrm{~h}$ and stained the bacteria with propidium iodide (PI) and SYTO9 (Live/Dead Bac-Light Bacterial Viability Kit, Molecular Probes, L-13152, Invitrogen). PI can stain DNA or RNA specifically to identify dead cells and SYTO9 with green fluorescent can indicate the viable cells. ${ }^{[1]}$ We observed the samples under a confocal microscopy (Zeiss LSM 710, Germany) at wavelengths of $488 \mathrm{~nm}$ and $568 \mathrm{~nm}$ for excitation and $530 \mathrm{~nm}$ (green) or $630 \mathrm{~nm}$ (red) for emission respectively. 


\section{Animal Model and Therapy Effect}

We developed acute bacteria-induced peritonitis model in BALB/c mice (SPF grade, female, 20 g, HFK Bioscience Co., Ltd, Beijing) to evaluate the in vivo treatment effect of A-GNPs synthesized in the lab (lA-GNPs) and in vivo (vA-GNPs). We cultured E. coli and MDR E. coli $\left(2 \times 10^{6} \mathrm{CFU} / \mathrm{mL}\right)$ in logarithmic proliferation phase and resuspended the bacteria in LB medium and mixed with $5 \mathrm{wt} \%$ yeast solution in equal volume. We divided the mice into 12 groups $(\mathrm{n}=12)$ and injected $500 \mu \mathrm{L}$ bacteria suspension (6 groups for $E$. coli and 6 groups for MDR E. coli) in the minimum lethal dose into the peritoneal cavity of the mice to build the acute peritonitis model. We administered $200 \mu \mathrm{L}$ saline (negative control group), ABA (4 $\mathrm{mg} / \mathrm{mL}), \mathrm{HAuCl}_{4}(10 \mathrm{mg} / \mathrm{mL}), \mathrm{AA}-\mathrm{GNPs}(2 \mathrm{mg} / \mathrm{mL})$, and both ABA and $\mathrm{HAuCl}_{4}$ (volume ratio 1:1) and levofloxacin (2 $\mathrm{mg} / \mathrm{mL}$, positive control group) by intragastric gavage after $1 \mathrm{~h}$ and $6 \mathrm{~h}$. To protect the activity of the amino group on ABA, we first gavage $\mathrm{HAuCl}_{4}$ into the stomach, and then gavage $\mathrm{ABA}$. The GNPs synthesized in the stomach can go down and reach the intestine where the GNPs can penetrate the intestinal epithelium and enter the blood stream via the interface between the intestinal epithelium and the capillary endothelium. By traveling through the circulatory system, the GNPs could reach the capillary of the peritoneum and enter the peritoneal cavity via the interface between the vascular endothelium and the peritoneal epithelium. At different time intervals (12, 24, 48, and 72h), we measured and recorded the bodyweight of the mice and euthanized 3 mice of the treatment group randomly. We resected the organs at $12 \mathrm{~h}$ for the control group and $72 \mathrm{~h}$ for the nanoparticle administration groups after the infection. We divided the resected organs (the heart, spleen, lungs, kidneys, liver) into two parts and ground one part of the organs with a grinder (G50, COYOTE) in PBS. We diluted the grounded tissue solution and spread the solution on LB agar plates to count the number of bacteria after incubation for $24 \mathrm{~h}$ at $37^{\circ} \mathrm{C}$. The other half of the organs are fixed in paraformaldehyde (4\% PFA) for $24 \mathrm{~h}$, embedded in paraffin, cross-sectioned, and stained by hematoxylin and eosin (HE) for histological analysis. Three normal mice without any infections were used as a normal group.

\section{Toxicity Evaluation and Pharmacological Study}

For further clinical applications, we tested the biocompatibility of $\mathrm{ABA}, \mathrm{HAuCl}_{4}$, and lA-GNPs synthesized in a highly acidic environment $(\mathrm{pH}=2)$, which was used to simulate the harsh environment in the stomach. As the GNPs will contact with blood directly or indirectly, we took blood compatibility evaluation of the lA-GNPs. ${ }^{[2]}$ We collected erythrocytes from fresh rat blood and centrifuged the samples at $1500 \mathrm{rpm}$ for $15 \mathrm{~min}$, and rinsed the samples thrice with phosphate-buffered saline (PBS, Solarbio, pH 7.4). We mixed $2 \mathrm{~mL}$ of centrifuged erythrocytes into $5 \mathrm{~mL}$ of saline and diluted $\mathrm{ABA}, \mathrm{HAuCl}_{4}$, and $\mathrm{lA}-\mathrm{GNPs}$ in saline to different concentrations. We added $100 \mu \mathrm{L} \mathrm{ABA}, \mathrm{HAuCl}_{4}$, or lA-GNPs into $100 \mu \mathrm{L}$ erythrocyte suspension and kept them for $3 \mathrm{~h}$ at $37^{\circ} \mathrm{C}$. We measured the optical density of the samples at $540 \mathrm{~nm}$ (OD540nm) by a microplate reader (Tecan infinite M200) after centrifugation at $1500 \mathrm{rpm}$ for 5 
$\min$.

We evaluated the in vitro cytotoxicity of lA-GNPs by culturing human aortic fibroblast cells (HAF) and NIH-3T3 cells $\left(10^{5}\right.$ cells $\left./ \mathrm{mL}\right)$ in Dulbecco's Modified Eagle Media (DMEM) containing 10\% fetal bovine serum (FBS, Invitrogen, USA) and $1 \%$ penicillin-streptomycin (PS, MP Biomedicals, USA) with $5 \% \mathrm{CO}_{2}$ at $37{ }^{\circ} \mathrm{C}$ with $\mathrm{ABA}, \mathrm{HAuCl}_{4}$, or lA-GNPs $(60 \mu \mathrm{g} / \mathrm{mL})$ for $3 \mathrm{~d}$. We fixed the cells with $4 \%$ paraformaldehyde solution (PFA, Leagene) for $10 \mathrm{~min}$ and stained the cells with Phalloidin /Hoechst (Dojindo, Japan). We observed the morphologies of the cells and assessed the cell density by confocal microscopy. All the experiments were performed in triplicate.

To evaluate the pharmacology of the lA-GNPs, BALB/c mice (SPF grade, female, 20 g, HFK Bioscience Co., Ltd, Beijing) experienced overnight fast were used for the intragastric administration experiment. We divided the mice into four groups ( $\mathrm{n}=$ 24) randomly and administered lA-GNPs (15 mg/mL), and both ABA (32 mg/mL) and $\mathrm{HAuCl}_{4}(80 \mathrm{mg} / \mathrm{mL})$ with different volume ratios (1:3, 1:1 and 3:1), which could react and yield GNPs in vivo by oral gavage. At different time points $(1,2,6,12,18$, 24, 48 and $72 \mathrm{~h}$ ) after the drug administration, the mice were sacrificed. We evaluated the distribution of GNPs in various organs by measuring the content of gold in the tissues using ICP. After different time points (5, 30, and $90 \mathrm{~min}$ ), we observed the appearance and distribution of vA-GNPs by gathering the nanoparticles from the cavity of the stomach and the intestine and characterizing them by TEM.

To study the toxicity of A-GNPs, we divided mice into five groups $(\mathrm{n}=15)$ randomly and treated the mice with oral gavage of saline, $\mathrm{ABA}(32 \mathrm{mg} / \mathrm{mL}), \mathrm{HAuCl}_{4}$ (80 mg/mL), lA-GNPs (15 mg/mL), and both ABA and $\mathrm{HAuCl}_{4}$ (volume ratio 1:1), respectively. We euthanized the mice from each group at different time points $(6,12$, 24, 72, and $168 \mathrm{~h}$ ) and collected the orbital blood samples for liver function (alanine aminotransferase, ALT; aspartate aminotransferase, AST), kidney function (creatinine, CR), immune response (interleukin 6, IL-6; interleukin 10, IL-10), and inflammatory reaction (tumour necrosis factor- $\alpha$, TNF- $\alpha$ ) analysis by ELISA kit (QuantiCyto) according to the manufacturer's instructions. We fixed the heart, liver, spleen, lung, kidney, brain and stomach in 4\% PFA, embedded the tissues in paraffin, cross-sectioned the embedded tissues at $5 \mu \mathrm{m}$, stained them with HE and then observed the samples by microscopy.

\section{Animal Care}

Mice were obtained from Beijing HFK Bioscience Co., Ltd (China) and raised in a specific pathogen-free environment. All animal studies were approved by the Institutional Animal Care and Use Committee, National Center for NanoScience \& Technology (IACUC, NCNST), and were performed in accordance to the prescribed procedures. 


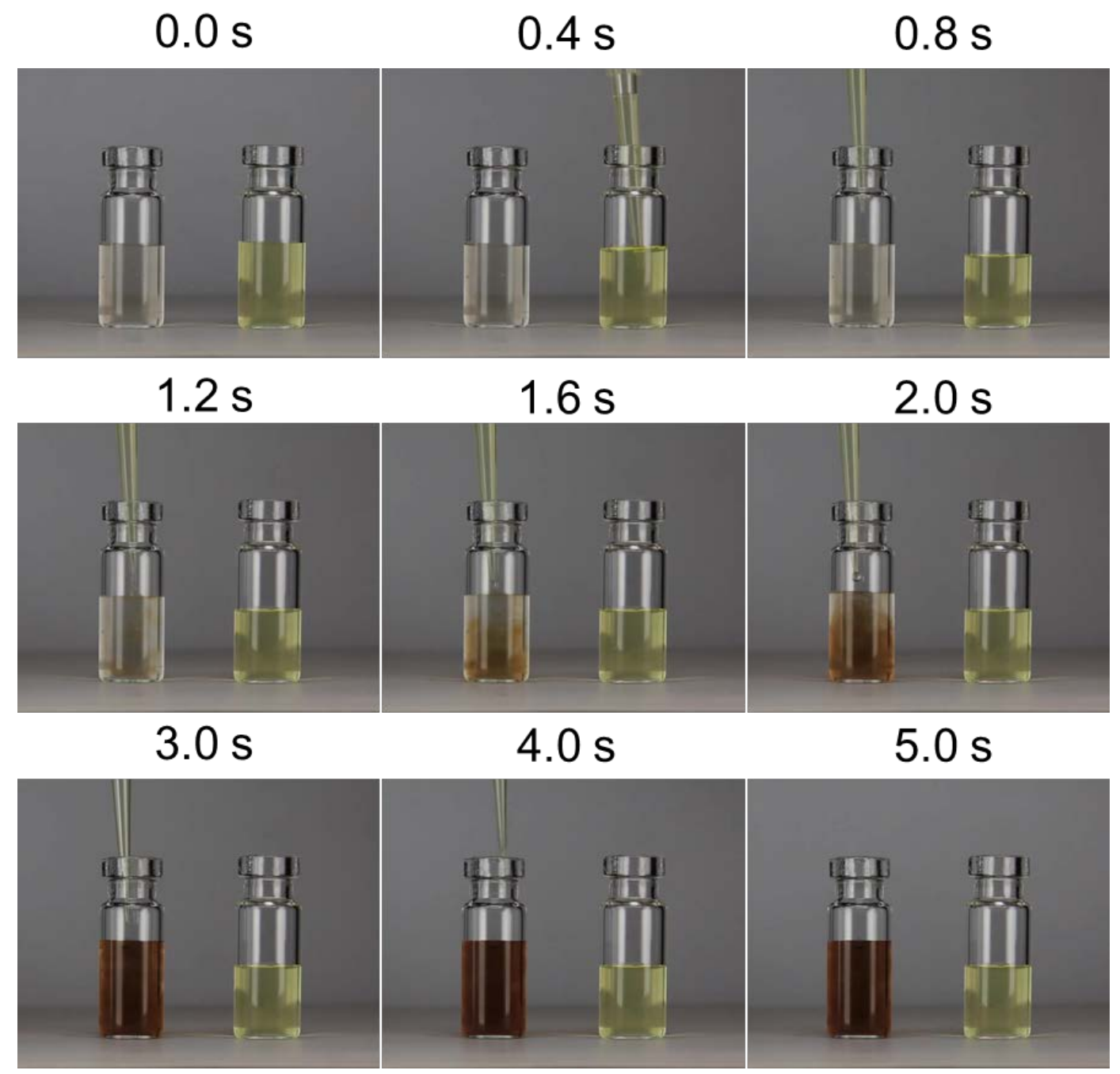

Figure S1. Time-lapse imaging shows the rapid synthesis of lA4-GNPs. 

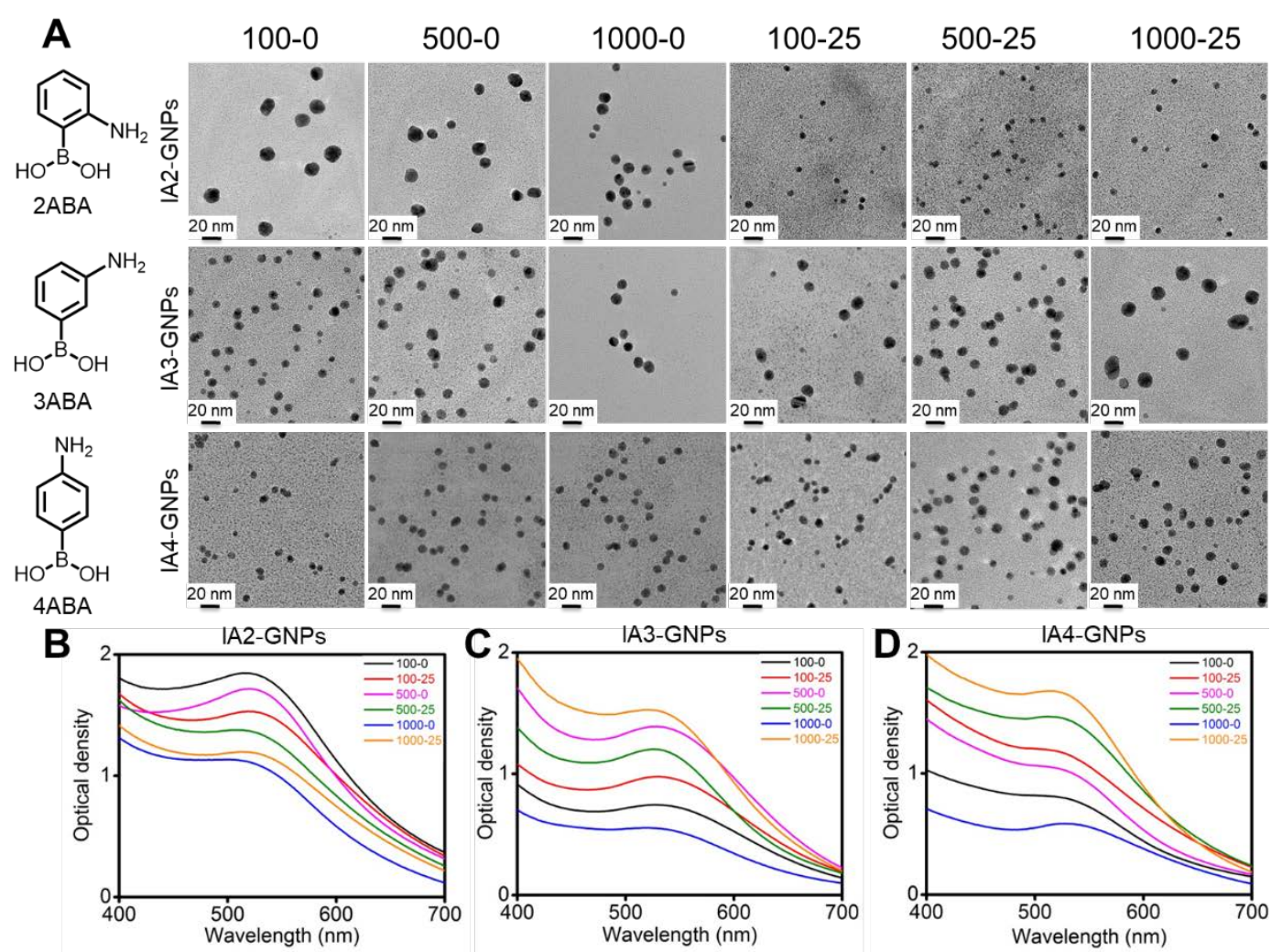

Figure S2. Characteristics of IA-GNPs synthesized at different rotation speeds (0 rpm, $500 \mathrm{rpm}$, and $1000 \mathrm{rpm})$ and temperatures $\left(0{ }^{\circ} \mathrm{C}\right.$ and $\left.25^{\circ} \mathrm{C}\right)$. (A) TEM images of lA-GNPs. (B) UV-visible spectrum of lA2-GNPs. (C) UV-visible spectrum of lA3-GNPs. (D) UV-visible spectrum of lA4-GNPs.
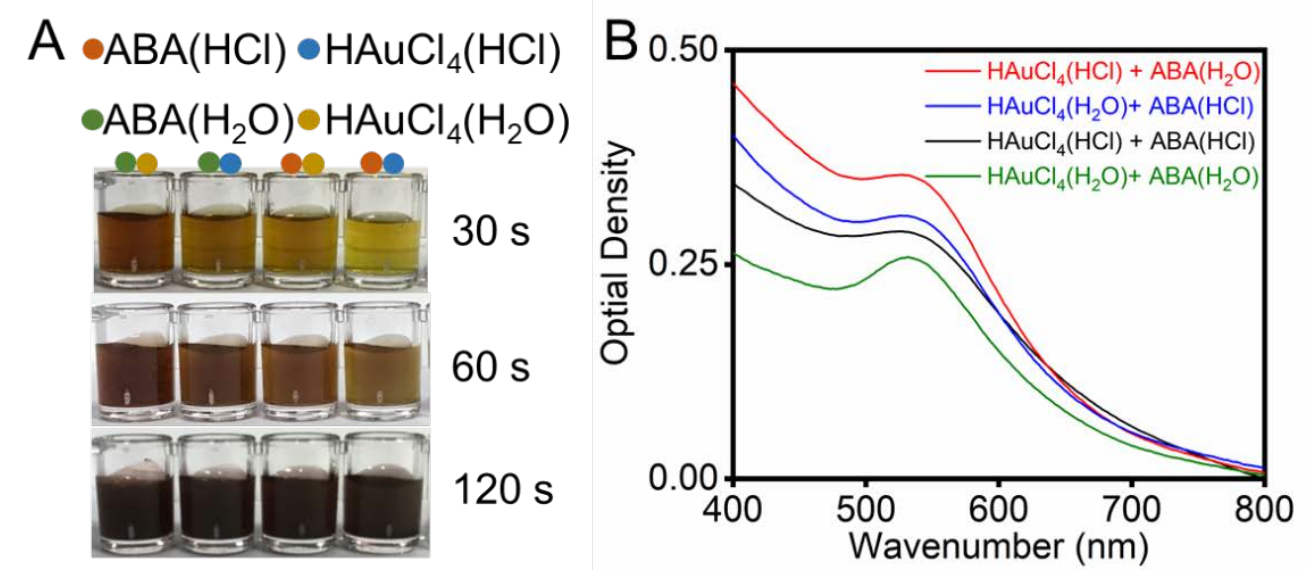

Figure S3. Characterization of lA4-GNPs synthesized at different conditions. (A) The reaction between $\mathrm{ABA}$ and $\mathrm{HAuCl}_{4}$ at different acidic conditions at different time points. (B) UV-visible spectra of the lA4-GNPs synthesized at different acidic conditions. 

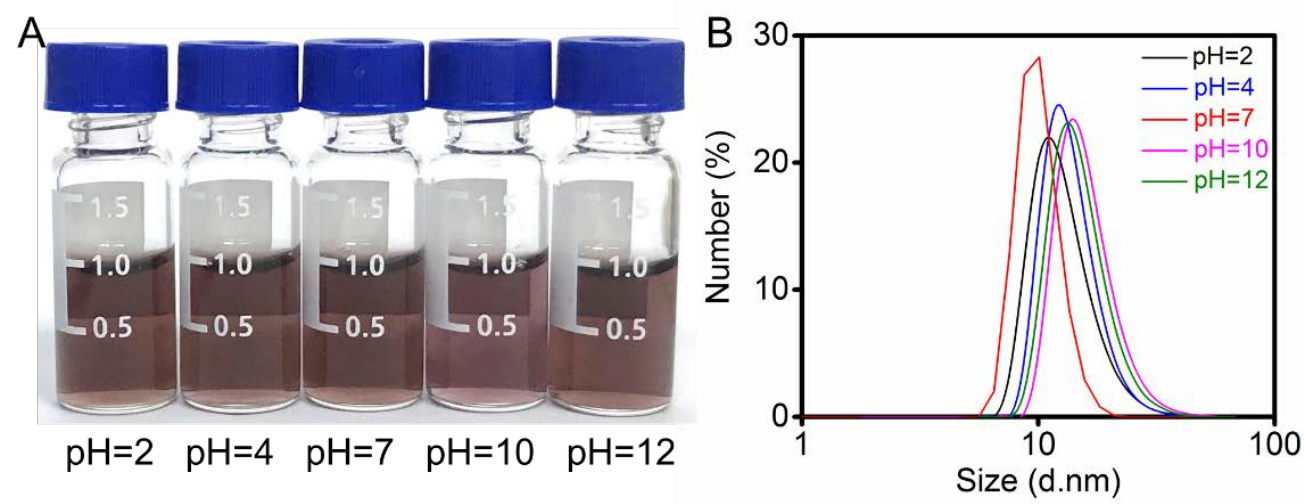

Figure S4. Characterization of the lA4-GNPs (synthesized at different pH conditions) after the storage at $4{ }^{\circ} \mathrm{C}$ for 12 months. (A) Photograph of the lA4-GNPs solution under normal light conditions. (B) DLS analyses of the lA4-GNPs.
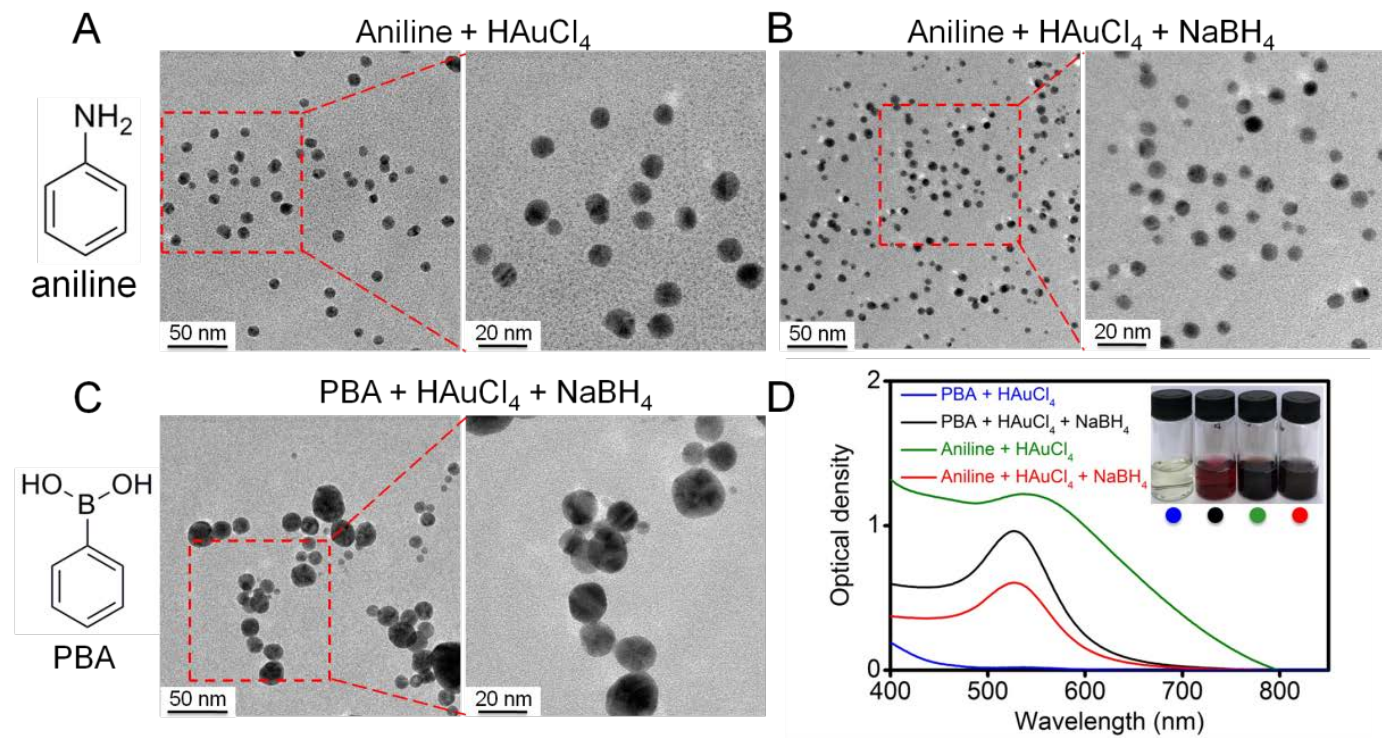

Figure S5. Characteristics of PBA- or aniline-capped GNPs. (A) TEM images of aniline-capped GNPs in the absence of $\mathrm{NaBH}_{4}$. (B) TEM images of aniline-capped GNPs in the presence of $\mathrm{NaBH}_{4}$. (C) TEM images of PBA-capped GNPs in the presence of $\mathrm{NaBH}_{4}$. (D) UV-visible spectrum and macro photograph of PBA- or aniline-capped GNPs with or without $\mathrm{NaBH}_{4}$. 


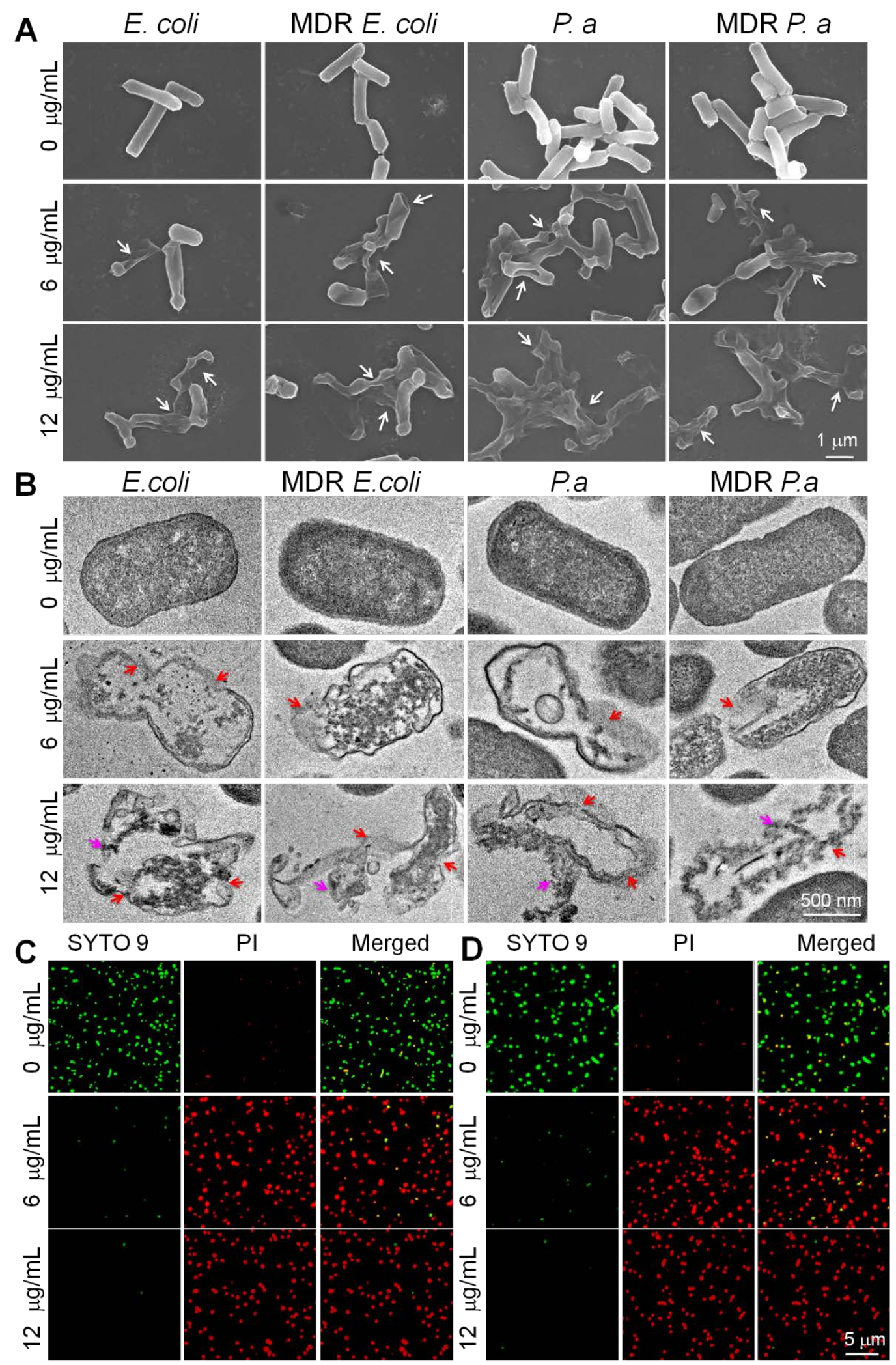

Figure S6. Observation of lA-GNPs-induced disruption of bacterial cell wall. (A) SEM characterizes the morphology of Gram-negative bacteria treated by different concentrations of lA-GNPs. White arrows point to the collapsed bacteria cell wall. (B) The morphology of Gram-negative bacteria treated by different concentrations of lA-GNPs is characterized by TEM. Red arrows indicate the blurred or disappeared 
bacteria cell wall. Pink arrows indicate the leakage of nucleic acids. Monitoring lA-GNPs-induced permeability of the (C) E. coli and (D) MDR E. coli bacterial cell membranes by SYTO9/PI staining.

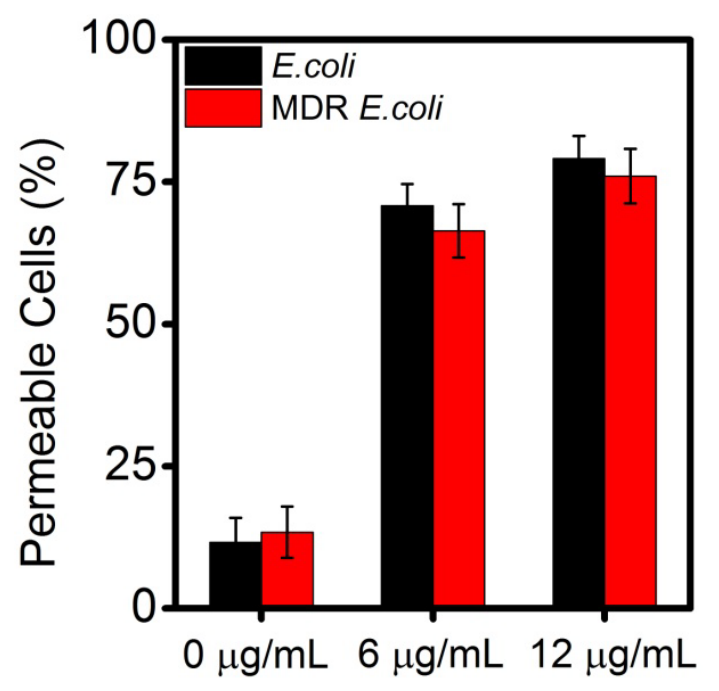

Figure S7. Observation of lA-GNPs-induced permeability of bacterial cell membranes indicated by PI staining. 


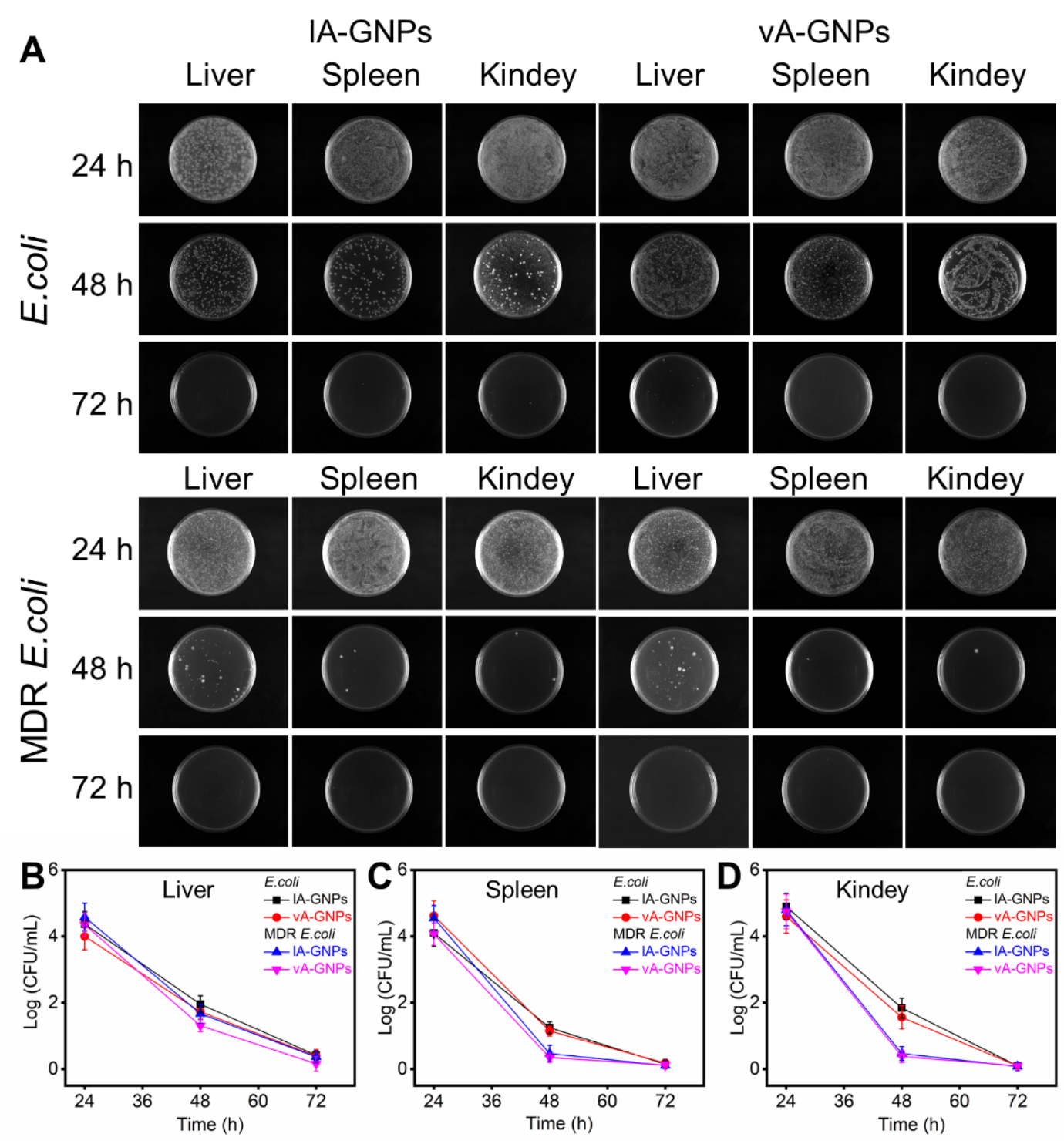

Figure S8. In vivo evaluation of the therapeutic effects of vA-GNPs and lA-GNPs against Gram-negative bacterial infections is demonstrated by counting bacteria colony on LB agar plates. (A) Bacteria in the organs of mice with an acute peritoneal infection of E. coli or MDR E. coli and treated by the GNPs synthesized in the lab (lA-GNPs) and in vivo (vA-GNPs) at different time points. Bacteria within (B) liver (C) spleen, and (D) kidney of mice after treatment with vA-GNPs or lA-GNPs for different periods are counted and plotted. 

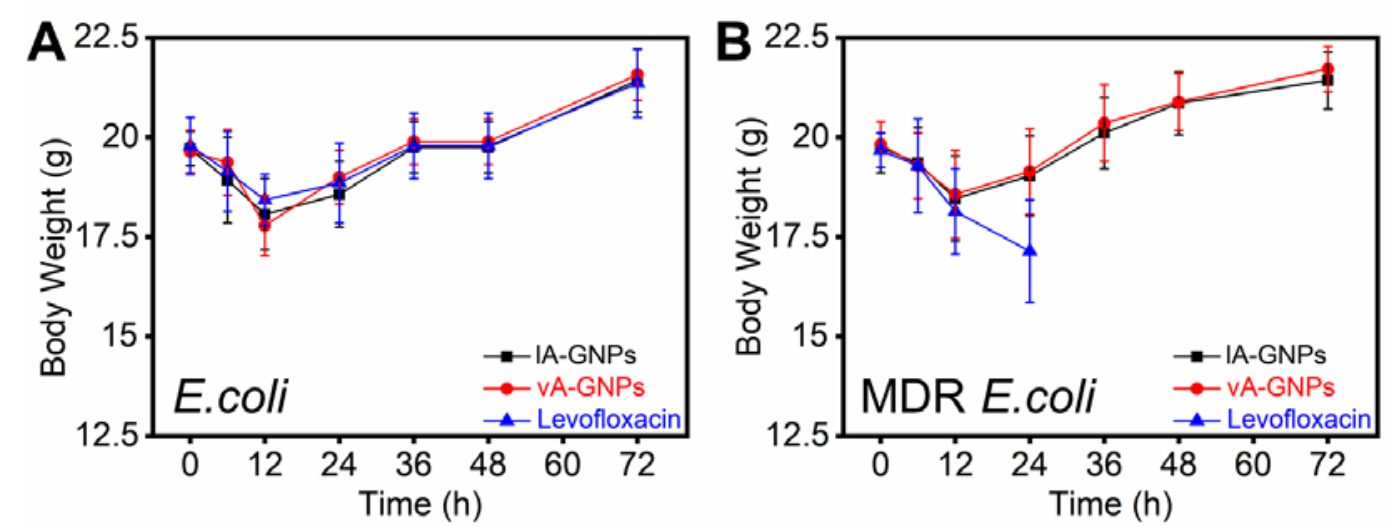

Figure S9. Body weight indicates the in vivo therapeutic effects of vA-GNPs, lA-GNPs and levofloxacin against Gram-negative bacterial infections. Bodyweight changes during the treatment by the A-GNPs or levofloxacin after (A) E. coli or (B) MDR E. coli infection is plotted respectively.
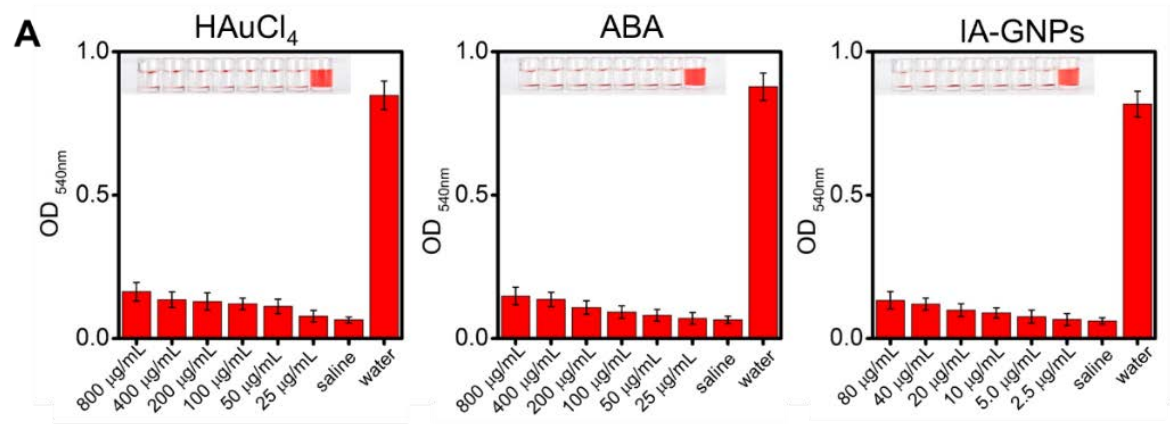

B Rhodamine Phalloidin

Hoechset

Merge

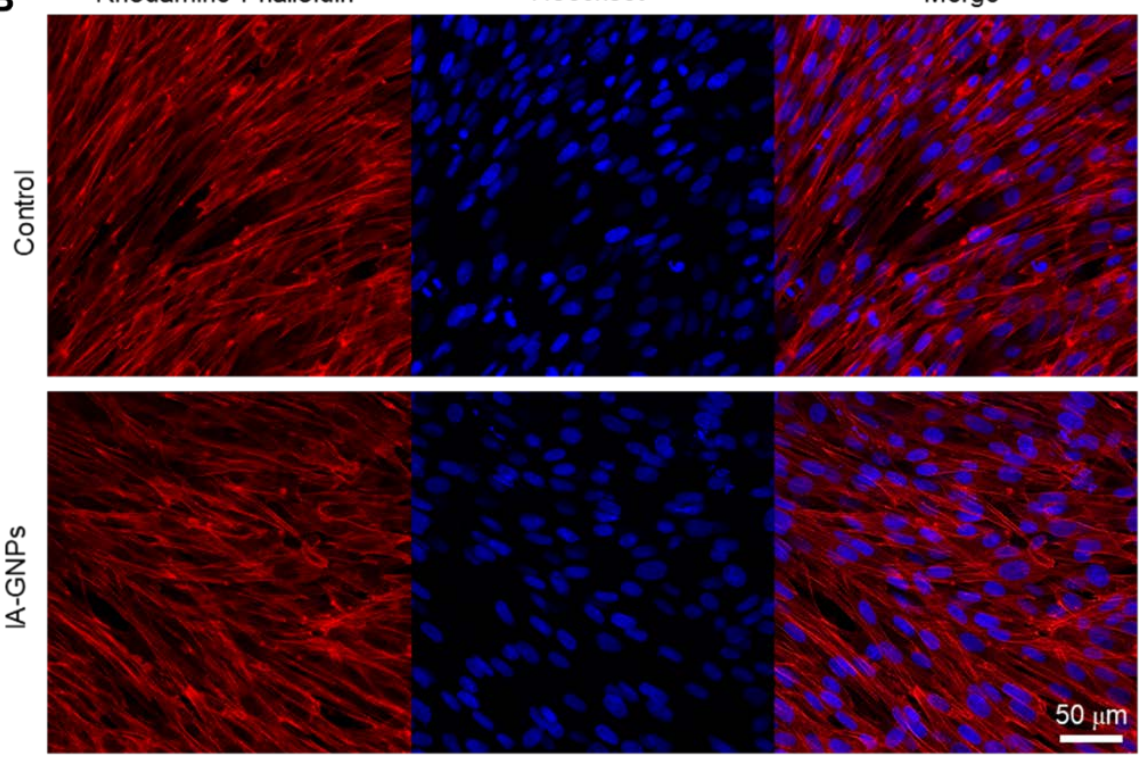

Figure S10. Biocompatibility of ABA, $\mathrm{HAuCl}_{4}$, and lA-GNPs. (A) Fresh rat erythrocytes are incubated with different concentrations of $\mathrm{ABA}, \mathrm{HAuCl}_{4}$, or lA-GNPs. Saline is used as a negative control and water as a positive control. (B) Laser scanning confocal microscopy (LSCM) images of HAF cells cultured with lA-GNPs. 

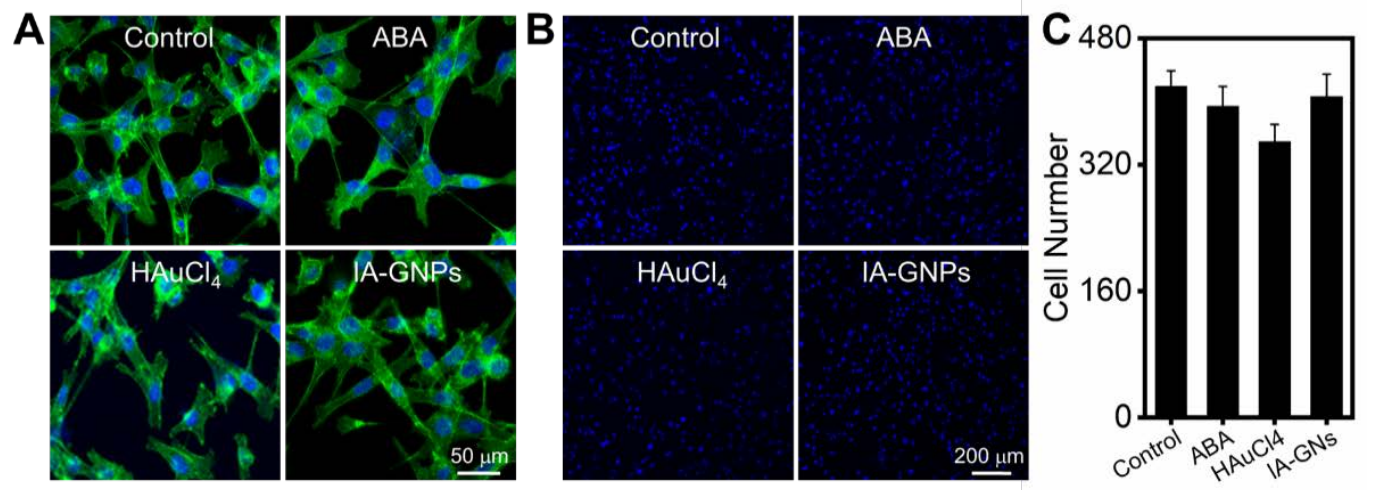

Figure S11. Cytotoxicity of ABA, $\mathrm{HAuCl}_{4}$, and lA-GNPs. (A) LSCM images of $\mathrm{NIH}-3 \mathrm{~T} 3$ cells cultured with ABA, HAuCl 4 , or lA-GNPs. (B) The density of NIH-3T3 cells is analyzed by counting the cell nuclei. The cell nuclei are stained by Hoechst 33342. (C) The number of NIH-3T3 cells is analyzed by counting cell nuclei. The data are from the mean of each treatment group (Mean $\pm S D, n=3$ ). 

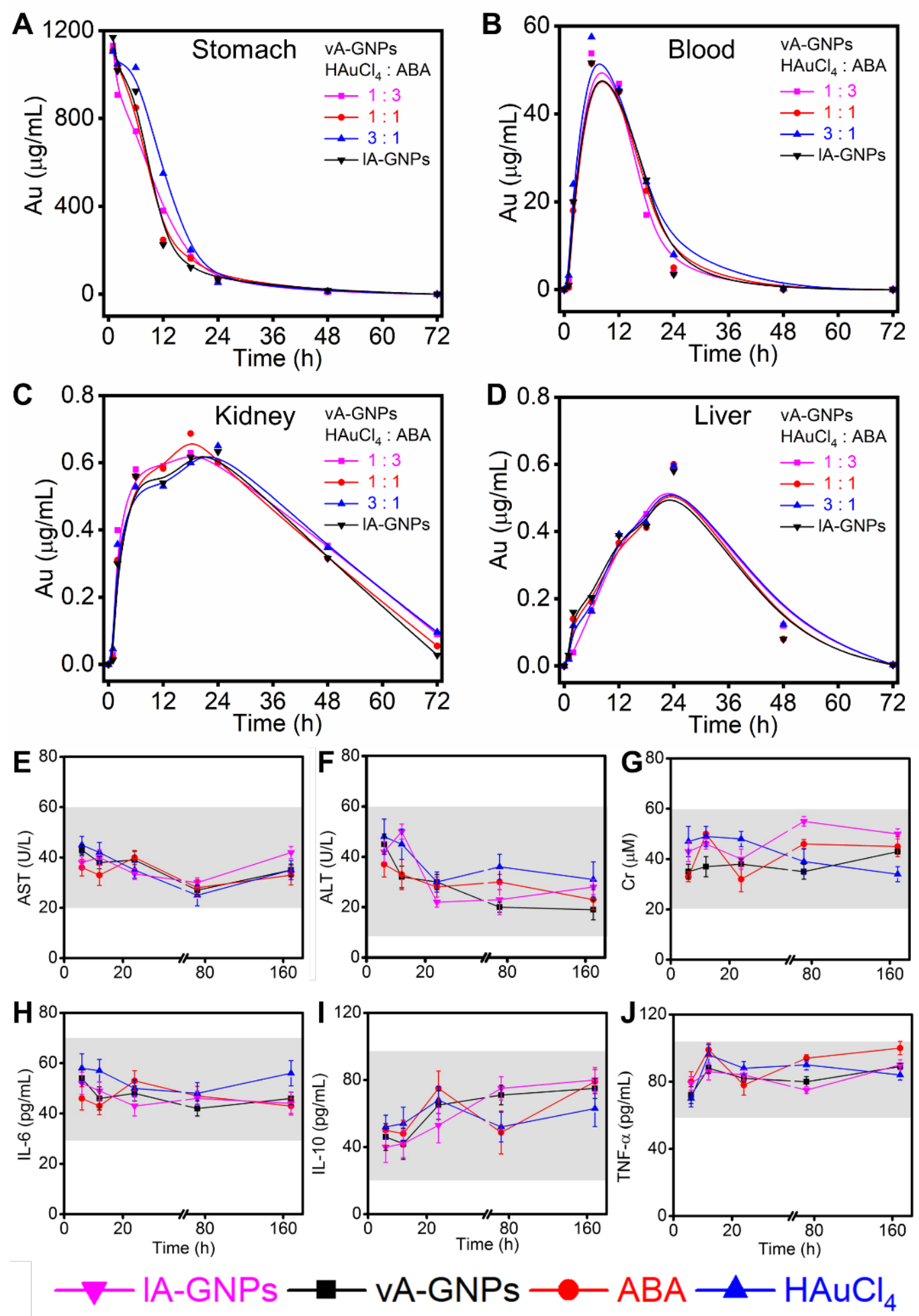

Figure S12. Pharmacological study and toxicity evaluation of vA-GNPs and lA-GNPs. Pharmacokinetic curves in (A) stomach, (B) blood, (C) kidney, and (D) liver of vA-GNPs synthesized by different ratios of $\mathrm{HAuCl}_{4}(80 \mathrm{mg} / \mathrm{mL})$ and $\mathrm{ABA}$ (32 $\mathrm{mg} / \mathrm{mL}$ ) are compared with the curves of lA-GNPs $(15 \mathrm{mg} / \mathrm{mL})$ after a single dose of oral administration to mice. The serum levels of (E) ALT, (F) AST, (G) Cr, (H) IL-6, (I) IL-10, and (J) TNF- $\alpha$ in mice treated by vA-GNPs, lA-GNPs, $\mathrm{HAuCl}_{4}$ or ABA at different time points are recorded and plotted. The normal range of each parameter is 
marked by a grey background. (alanine aminotransferase, ALT; aspartate aminotransferase, AST; creatinine, CR; interleukine-6, IL-6; interleukine-10, IL-10; tumor necrosis factor, TNF- $\alpha$ ).

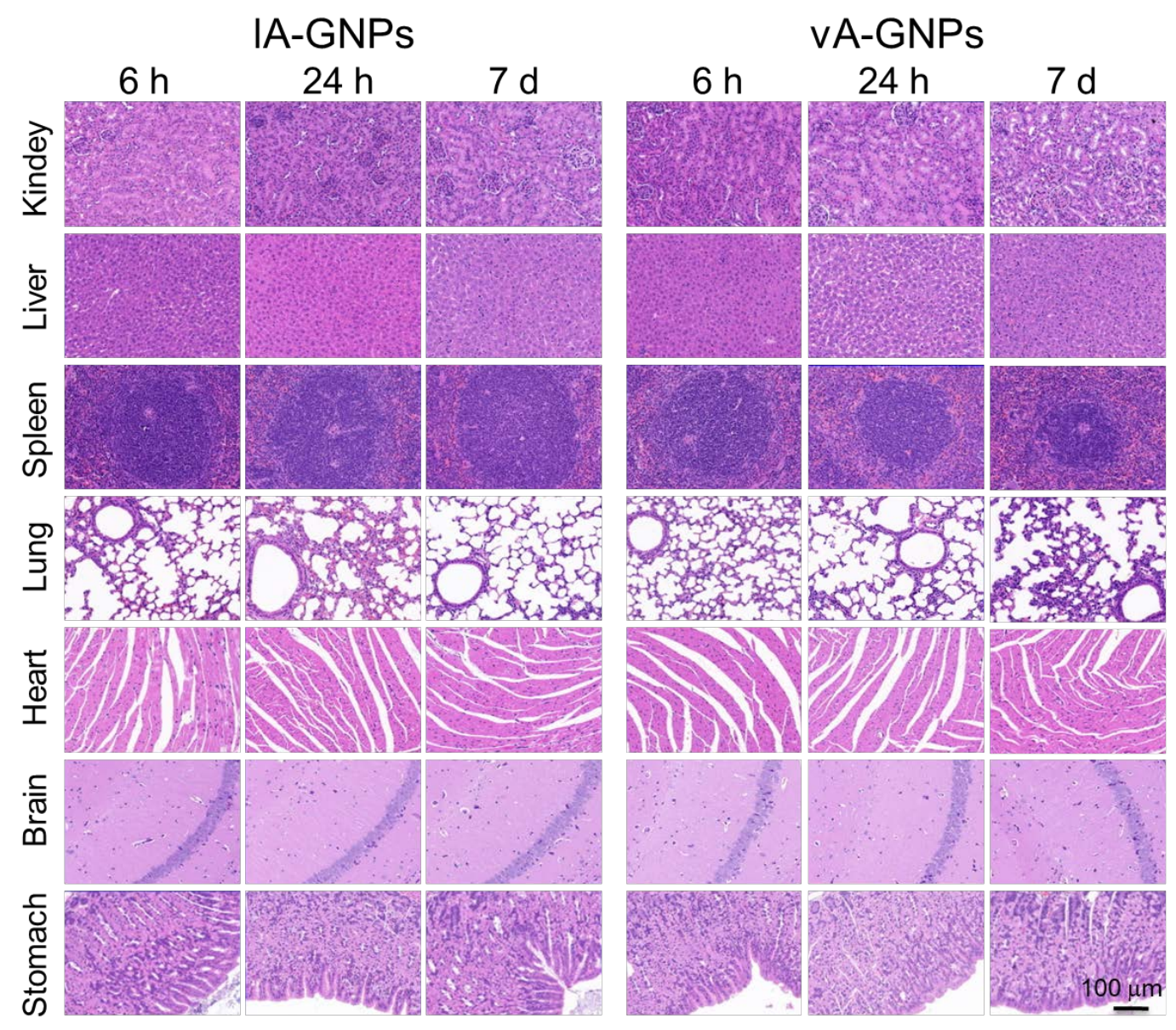

Figure S13. HE staining of excised tissue sections of vA-GNPs- or lA-GNPs-treated mice. The scale bar equals $100 \mu \mathrm{m}$. 
Table S1. Comparison of different methods for synthesizing GNPs.

\begin{tabular}{|c|c|c|c|}
\hline Synthesis condition & $\begin{array}{l}\text { Nanoparticle } \\
\text { size }\end{array}$ & $\begin{array}{l}\text { Reducing } \\
\text { agent }\end{array}$ & References \\
\hline $\begin{array}{l}90{ }^{\circ} \mathrm{C} \text { oil bath } \\
\text { for } 35 \mathrm{~min}\end{array}$ & $2.5 \pm 0.3 \mathrm{~nm}$ & Glutathione & {$[30-31]$} \\
\hline $\begin{array}{l}0^{\circ} \mathrm{C} \text { ice bath } \\
\text { for } 120 \mathrm{~min}\end{array}$ & $2-10 \mathrm{~nm}$ & Sodium borohydride & [32-33] \\
\hline $\begin{array}{l}100{ }^{\circ} \mathrm{C} \text { oil bath } \\
\text { for } 15 \mathrm{~min}\end{array}$ & $10-100 \mathrm{~nm}$ & Sodium citrate & [34] \\
\hline $\begin{array}{l}\text { Any temperature } \\
\text { within } 5 \mathrm{~s}\end{array}$ & $10 \mathrm{~nm}$ & Without reducing agent & In this paper \\
\hline
\end{tabular}

Table S2. Strains of bacteria used in this study.

\begin{tabular}{cc}
\hline Strains & Source \\
\hline Escherichia coli (E. coli) & ATCC 11775 \\
Klebsiella pneumoniae (K. p) & ATCC 13883 \\
Pseudomonas aeruginosa (P. a) & ATCC 27853 \\
\hline
\end{tabular}

ATCC, American Type Culture Collection

Table S3. The profiles of the corresponding drug-resistant antibiotics for each MDR strain used in this study.

\begin{tabular}{cccc}
\hline & MDR E. coli & MDR K. $p$ & MDR P. a \\
\hline \multirow{4}{*}{ Antibiotics } & Penicillin & Penicillin & Oxacillin \\
& Oxacillin & Oxacillin & Imipenem \\
& Vancomycin & Vancomycin & Vancomycin \\
& Cefotaxime & & Gentamicin \\
& Gentamicin & & \\
\hline
\end{tabular}

Table S4. Antibacterial activities of A-GNPs synthesized under different conditions indicated by MIC $(\mu \mathrm{g} / \mathrm{mL})$.

\begin{tabular}{cccccccc}
\hline & Materials & $100-0$ & $500-0$ & $1000-0$ & $100-25$ & $500-25$ & $1000-25$ \\
\hline \multirow{3}{*}{ E. coli } & IA4-GNPs & 4 & 1 & 4 & 4 & 4 & 8 \\
& IA3-GNPs & 1 & 2 & 2 & 4 & 8 & 2 \\
& IA2-GNPs & 4 & 4 & 4 & 4 & 4 & 8 \\
\hline \multirow{2}{*}{ MDR E. coli } & IA4-GNPS & 4 & 2 & 4 & 4 & 4 & 4 \\
& IA3-GNPS & 12 & 8 & 12 & 8 & 8 & 8
\end{tabular}


Table S5. Pharmacokinetic parameters of vA-GNPs synthesized by ABA and $\mathrm{HAuCl}_{4}$ in different volume ratios as compared with lA-GNPs after a single dose oral administration to mice.

\begin{tabular}{ccccc}
\hline \multirow{2}{*}{$\begin{array}{c}\text { Pharmacokinetic } \\
\text { Parameters }\end{array}$} & \multicolumn{3}{c}{$\mathrm{ABA}_{\mathrm{H} \text { HAuCl}}$ (VA-GNPs) } & \\
\cline { 2 - 4 } & $1: 3$ & $1: 1$ & $3: 1$ & \\
\hline $\mathrm{C}_{\max }(\mu \mathrm{g} / \mathrm{mL})$ & 57.52 & 51.50 & 53.75 & 51.57 \\
$\mathrm{~T}_{\max }(\mathrm{h})$ & 6 & 6 & 6 & 6 \\
$\mathrm{AUC}(\mathrm{h} \times \mu \mathrm{g} / \mathrm{mL})$ & 898.9 & 784.8 & 764.3 & 786.2 \\
$\mathrm{~T}_{1 / 2}(\mathrm{~h})$ & 16.97 & 17.39 & 16.11 & 18.02 \\
\hline
\end{tabular}

\section{References}

1 J. R. Morones-Ramirez, J. A. Winkler, C. S. Spina, J. J. Collins. Sci. Transl. Med. 2013, 5,181-190.

2 M. C. Daniel, J. Ruiz, S. Nlate, J. C. Blais, D. Astruc. J Am Chem Soc, 2003, 125, 2617-2628. 